OPEN ACCESS

Edited by:

Shaunak Sastry,

University of Cincinnati, United States

Reviewed by:

Rati Kumar

Central Connecticut State University,

United States

Victoria Team,

Monash University, Australia

Maria Beatriz Torres,

Mercyhurst University, United States

Raihan Jamil,

Zayed University,

United Arab Emirates

${ }^{*}$ Correspondence:

Smita Misra

smisra@unc.edu

Specialty section: This article was submitted to Health Communication, a section of the journal Frontiers in Communication

Received: 16 May 2019 Accepted: 22 May 2020

Published: 02 July 2020

Citation: Misra S (2020) A Critical Reflexive Account From Participatory Theater With Asylum Seekers: Lessons for

Framing Trauma and Resilience in

Refugee Status Determination

Front. Commun. 5:40.

doi: 10.3389/fcomm.2020.00040

\section{A Critical Reflexive Account From Participatory Theater With Asylum Seekers: Lessons for Framing Trauma and Resilience in Refugee Status Determination}

\author{
Smita Misra* \\ Department of Communication, University of North Carolina, Chapel Hill, NC, United States
}

Critical Health Communication scholars can play a significant role in the asylum seeking process by expanding the legal understanding of migrant trauma. Legal processes like Refugee Status Determination (RSD) define the course of an asylum seeker's life. Legal determinations hinge on the persuasiveness of narratives of persecution to decide on the legitimacy of asylum claims. Participatory methods, such as participatory theater, either support or resist legal processes by drawing on narratives of trauma or community engagement, respectively. Methods that rely on trauma narratives validate notions of individual suffering, while methods that use community engagement address the social and communal dimensions of health, including isolation. This essay develops a critical, reflexive account of my situated practices as a theater practitioner working with asylum seekers, and later, as a character reference for my participants' legal claim. I show how participatory projects focusing exclusively on promoting migrant resilience through participation can fail to engage with the power that RSD has to determine the course of migrant lives. Importantly, the legal framework of RSD frames an asylum seeker's every move through the lens of persecution and trauma. As my critical reflections demonstrate, participatory practitioners working with asylum seekers must be aware of how the goals of their engagement may interact with the limitations of the legal process. Such awareness demands strategic forms of engagement aimed at shaping the legal understanding of migrant trauma and persecution.

Keywords: reflexivity, asylum seekers, refugees, trauma, resilience, performance studies, refugee status determination

\section{INTRODUCTION: MOTIVATION AND PROBLEM}

What does it mean to be a "true" refugee? Sparking countless debates over several decades, the word "refugee" is one of the most fraught and contested terms of the new millennia. Most nation-states have continued to define the refugee in terms of political persecution. However, critics argue that the narrow legal definition of the refugee, and its even narrower implementation, calls for a radical rethinking of the legal category. The notion of trauma is closely stitched into the cultural and legal understanding of political persecution. Legal processes like Refugee Status Determination (RSD) rely on the production 
of trauma, while activists, artists, and community practitioners argue that refugees are "more than their trauma." Caught between competing discourses of trauma, resilience, persecution, and freedom, I argue that community practitioners, like those working in health communication, must critically reflect on how legal structures depend on refugee trauma, including medical diagnoses of post-traumatic stress disorder (PTSD), even if they have good reasons for disengaging from it.

Within a contemporary "culture of disbelief" (Gibson, 2013; Jubany, 2017) that treats the testimonies of asylum seekers as false, PTSD is often deployed as a strategy to validate the suffering of asylum seekers (Ticktin, 2011; Pestre, 2012; Willen, 2012). In particular, North American and European immigration courts rely on diagnoses and discourses of trauma as a way to legitimize the political persecution of refugees (Ticktin, 2011; Pestre, 2012; Willen, 2012). The existing literature in refugee health communication focuses on the development and evaluation of targeted and tailored health messages to improve migrant health. It does not consider how the taken-for-granted nature of illness (Lupton, 1994), like refugee trauma, is reproduced in the expectations of legal professionals like immigration judges and lawyers. That is, asylum seekers who fail to meet the law's narrow definition of persecution through the language of trauma and diagnoses of PTSD are unlikely to be successful in their asylum claims. Engaging with the power of courts to shape refugee identity and health, I follow others (Lupton, 1994; Zoller and Kline, 2008; Dutta, 2010) in arguing that Critical Health Communication (CHC) practice must expand its focus from illness-affected populations to include systemic players.

Health communication scholarship has been comparatively slow to address the health of refugees and asylum seekers. Searching "refugee" in The Journal of Health Communication and The Health Communication Journal yields a mere 36 results, while searching "asylum seeker" yields zero. However, the fascination with refugee trauma is reflected in research funding schemes. For example, the National Institute of Mental Health (NIMH) has funded 26 projects in the 2018-2019 fiscal year containing the word "refugee" in the abstract. More than a third of these projects were studying refugee trauma in some form, while the remaining results were focused on HIV or diabetes. This suggests that of the limited health research on refugees, a large portion focuses on their trauma. In addition to creating troubling standards of health and illness for migrants seeking asylum, it also places indirect pressures on practitioners and researchers who work with refugees and asylum seekers. An underlying assumption of refugee trauma informs the work of many community practitioners.

Some scholars have espoused a counter-narrative of refugee resilience (Coleman, 2012; Simich and Andermann, 2014). Challenging the ubiquity of trauma, proponents of the refugee resilience perspective argue that " $[\mathrm{t}]$ hough challenging to survive under [severe] circumstances, many refugees do survive in their adopted lands, and many even thrive" (Simich and Andermann, 2014 , p. 2). The cultural discourses and expectations of the trauma/ resilience dichotomy comes to influence asylum seekers through the people who mediate their interactions with social, communal, and legal structures. This includes the work of lawyers and social workers. It can also include the work of researchers and community participatory practitioners.

In this critical, reflexive account, I reflect on my role as a theater practitioner working with asylum seekers, and later, as a character reference for my participants' legal claim. Departing from participatory theater projects that focus predominantly on promoting migrant resilience and addressing social isolation, I engage with the structural conditions of Refugee Status Determination (RSD). In RSD, an asylum seeker's life narrative is weighed on a scale of persecution and trauma. I conclude that participatory practitioners, like $\mathrm{CHC}$ scholars working with asylum seekers, must negotiate the goals of promoting resilience while setting up their participants to succeed within the narrow legal definitions of RSD. This involves responding to and shaping the legal understanding of migrant trauma and persecution.

\section{BUREAUCRATIC PERFORMANCE: SHIFTING FROM REFUGEE TRAUMA TO LEGAL EXPECTATIONS}

RSD requires asylum seekers to perform their persecution (Jeffers, 2008; Wake, 2013; Cox, 2014). This means that asylum seekers are not only responsible for dictating their narratives of persecution but, more importantly, of convincing the judges of their persecution. Alison Jeffers calls this, "bureaucratic performance": "Asylum seekers whose stories have not persuaded the authorities of their authenticity have been unable to perform to the required standard and stand accused of being unconvincing in the bureaucratic performance of those stories" (Jeffers, 2008, p.217). For Jeffers, bureaucratic performance takes place within the legal structures of immigration courts and hearings. Within these courtrooms, an asylum seeker's personal testimonial is central to the claim of persecution. Often, these narratives of persecution rely on the language of trauma and evidence of post-traumatic stress disorder (PTSD) to make a convincing case. In other words, bureaucratic performance conceives of immigration judges as audience members in the performance of trauma.

Analyzing refugee trauma through a lens of performance studies shifts our understanding of trauma as a condition that is inherent to refugees to a condition that has been established through a series of repeated acts for audiences. This brings up questions of who is considered an authentic refugee, what is considered to be authentic trauma, and who is allowed to decide. The repetition and reliance on trauma narratives in immigration courts suggests that immigration judges find narratives of trauma to be compelling evidence of persecution. Shifting the focus of analysis from migrant trauma to expectations of trauma enables us to see how performances of trauma are coerced from migrants in RSD to convince a legal audience. To address the systemic determinants of migrant health, I contend that critical health communication strategy needs to expand its intended audience from the illness-afflicted population, migrants, to systemic power players, like immigration judges and lawyers. 


\section{DISCUSSION}

\section{Participatory Theater Practice and Social Expectations of Trauma}

The following reflexive case study highlights the tensions that arise when theater practitioners attempt to address the health concerns of asylum seekers by focusing on social well-being and community engagement. As I illustrate, the legal process of RSD frames the social engagement and well-being of asylum seekers as contradictory to their status as vulnerable and persecuted people. I draw on my embodied reflections to illustrate how practitioners can use discourses of trauma and resilience to expand the legal expectations of trauma elicited by bureaucratic performance.

Several years ago, I was involved in a community theater project in a country from the Global North. To protect the identities of my participants, I have omitted the details of my location and the organizations that I worked with. The theater production was a community-supported public project addressing the themes of migration. Consisting of 150 performers, the project involved the performance of stories by and about migrants. My role within the production included facilitating the participation of two young asylum seekers, pseudonymized here as Anisa and Adnan. I met Anisa and Adnan in my capacity as a volunteer at the local refugee aid organization. Volunteers had a number of different responsibilities to facilitate migrant integration. These included running theater workshops (as I did), helping with English skills, engaging them in community activities, attending lawyer's meetings, and helping to fill out legal paperwork. In training, volunteers like me were advised to avoid discussing sensitive or triggering subject matter with migrants. Topics to avoid included conversations about past lives, families back home, or journeys to the host country. In this way, the refugee organization actively resisted the expectations of trauma and persecution demanded by the legal processes of refugee determination- bureaucratic performance. In other words, they attended to trauma survivors by providing opportunities for them to escape from their trauma.

Theater, because of its focus on fun, games, and play, was thought to be one of the best mediums for such an escape. Since I had a performance background, a project manager at the NGO put me in touch with the artistic director of an upcoming community production. I was told that the theater director had approached the organization previously to recruit some migrants for the project. The NGO managers agreed that the play might be a positive, creative outlet for young people and agreed to bring them to the director's acting class to educate amateur actors on the lived experiences of migration. However, the director had little awareness of how to broach the topic of migrant lives. According to the managers, the group of young migrants, who were usually very chatty, were quiet and uncomfortable when they were asked to talk about their lives. The meeting was considered unsuccessful.

The NGO managers thought that I might be able to facilitate a collaboration between the theater and their organization. At our first meeting, the director explained to me, "what theater can do is help us empathize with refugees. We've all felt pain, we've all felt loss." The director wasn't alone. Theater with and about refugees is premised on the "authenticity" factor (Jeffers, 2008;
Wake, 2013; Cox, 2014). The "true" or "genuine" or "real" stories of asylum seekers are assumed to foster a sense of connection with the theater audience. And as witnesses to someone else's pain, audiences are supposed to feel empathy. What is left out of the narrative of "empathizing with refugees" is that the power to determine the authenticity of the narrative lies with the audience. Just like in bureaucratic performances, where refugee characters must convincingly portray refugee narratives, theater audiences find narratives of trauma most compelling (Jeffers, 2008; Wake, 2013).

The director sought to humanize migrants at a time when they were being demonized by mainstream politicians and press. However, his unsuccessful attempt to involve migrants pointed to the controversial ethics of making migrants uncomfortable by asking them to share painful stories. The default desire to focus on migrant pain brought to life Jeffers' argument that participatory theater practice risks recreating scenes of trauma for migrants who may be actors or audience members. As such, a key lesson for health communication scholars and theater practitioners alike is that performance easily mimics a legal process that understands persecution in terms of trauma. By expecting narratives of trauma, as the director had done, this participatory theater production risked solidifying the legal frameworks determining "authentic" refugee status.

At the same time, involvement in theater and performance can potentially play a significant role in addressing aspects of social isolation and its associated health outcomes. Asylum seekers are barred from a range of communal activities including schooling, college, and work (Thompson and Schechner, 2004; Balfour and Woodrow, 2013). This further prevents them from having access to community events that can help engage their participation in their host cities. Applied theater interventions, like the participatory project that I was involved in, aim to build community and address isolation for improved social and mental health (Conquergood, 1988; Salverson, 2001; Thompson, 2009; Balfour and Woodrow, 2013; Wake, 2013; Cox, 2014). The relevance of these ideals for my participants became apparent as we began to work together. For example, when Adnan found out that I was a theater student at a nearby university, he sought me out immediately. As documented by my field notes (S. Misra, field notes, February 24, 2014), he confided:

\footnotetext{
So you're in theater? I'd really like to act. Do you direct? I'm quite good. My sister and I used to always perform back home. We were the stars of our schools. Well, my sister was the smartest student in the entire school. She was always getting awards and flowers. She's a really good writer, so the teachers would ask her to give speeches to motivate the students... And I used to cause trouble, so they asked me why I wasn't like her...
}

Adnan said all at once. "But I like to be a clown," he smiled widely. "As you saw in the class. So if you ever need anyone for a play, let me know." It was clear from this first interaction that Anisa and Adnan were actively seeking out opportunities to be involved in the community. When I met them, they were volunteering at a food kitchen. This was a different relationship to theater than the one envisioned by the director and typically described in refugee performance literature (Jeffers, 2008; Wake, 2013; Cox, 2014). For 
Anisa and Adnan, theater was not a medium through which they could tell their stories- ones that would mimic or expand upon the stories they had to tell in their asylum claims. Instead, theater, like working in the food kitchen, served as a means of connection in the host country and as an opportunity to be recognized for their talent or service, not their vulnerabilities.

Adnan did not simply want to be a clown. He wanted to be a star. Rejecting the preparation we had done over almost 5 weeks, Adnan came to one of our final workshops with a fully developed stand-up routine. "Man, the Italians are so lazy," Adnan crooned in his monolog, "they didn't even finish building the Colosseum! I'm telling you, if you ever need anything built, do not hire an Italian builder..." Inspired by the comics he saw on television, Adnan wanted to entertain and be admired. The day after the production closed, he spent his limited funds traveling to London to audition for the X-Factor. Contrary to the assumptions of the theater director- who believed that theater could produce witnesses for migrant trauma- Anisa and Adnan wanted people to witness their talent.

As we prepared for the production, I did everything I could to steer clear of painful or traumatic subject matter- perhaps too strongly. Once, as I was working with Anisa, I asked her to think of a happy moment. But happiness is often stitched with sadness. The moments that brought Anisa joy, like cooking with her mom or laughing with her brothers, also reminded her of an abusive father. I noticed myself get nervous when Anisa got sad. I had resolved to not mimic bureaucratic performances in my theater work. In retrospect, and as I will discuss, my well-intentioned resolve to change topics whenever a conversation got heavy could have compromised Anisa and Adnan's asylum claim. My project was embedded in the bureaucratic process of asylum seeking. By seeking to resist the narratives of trauma in a participatory theater project, I risked going against the expectations of vulnerability and trauma set up by the refugee determination process. Instead, I had to hold the complexity of trauma, resilience, remembering, and forgetting. I had to be strategic- prepared to respond to the legal understanding of persecution.

\section{Participatory Theater Practice and the Legal Expectations of Trauma}

Four months after the production had ended, Anisa wrote to me saying that their asylum claim had been rejected. They had decided to appeal the decision and had asked me for references of support. This was not an unreasonable ask. It was expected that volunteers like myself would do what they could to help with an asylum seeker's court case by writing references, communicating with social workers, and attending lawyers' meetings. I wrote back to Anisa, asking what kinds of traits they were looking for. According to the letter from the immigration department, Anisa said they were rejected for reasons that included not being from a priority country and not being of a vulnerable age. The letter also cited that based on their participation in community activities like volunteering at a food kitchen and the theater project, they were deemed to be independent and confident enough to take care of themselves in their home countries.

I approached the NGO project managers for advice. They wrote: ...it is good to show local support in this way. I would hope they have approached staff at college and others who can also write letters of support. All it is, is a character reference in a sense... if relevant, you can mention whether this rejection is affecting them adversely and could comment that way. I am not sure what their chances are-somehow, I am not sure that [people of their nationality] are winning their claims (personal communication, August 26, 2014).

This moment shifted how I understood my engagement with my participants. By focusing exclusively on migrant resilience and well-being, I had failed to engage with the legal frameworks and logics of RSD whereby an asylum seeker's every move is analyzed through the lens of persecution and trauma. My audience was not simply the migrants I worked with, but also the courts who interpreted their activities. Recognizing that my role was to help the courts understand that resilience and trauma were not mutually exclusive, I desperately wrote a response to Anisa's request. This time, I framed her confidence and resilience in terms of trauma:

\begin{abstract}
... In my work with Anisa, I have had indications that her past experiences have severely affected Anisa's life. These things were disclosed to me within the privacy of our workshops during candid reflection when Anisa recollected memories in a stream of consciousness. After occasions like these, I had to provide other distractions so that she could regain control of herself... There is no doubt that Anisa is a dynamic, confident and well-spoken young woman. However, I have reason to believe that these are precisely the qualities that have led to her abuse in the past and are unfortunately, working against her, again... she needs help. She suffers from panic attacks and anxiety. By going back to XXX I believe she will be left to fend for herself against men in her family and community who are abusive and violent. It is for this reason, for her safety, health and future, that I ask you to reconsider your decision of rejecting her asylum claim. As a young woman her life will be put back in danger when she deserves a chance at being the productive asset to a society that she has the potential to be (personal communication, August 27, 2014).
\end{abstract}

At first, I was uncomfortable writing these letters. I revealed painful details from our conversations. Details that were confidential and not initially meant for public audiences. I consulted the project managers and Anisa and Adnan before sending my letters. Everyone agreed that my documents suited the circumstances and the siblings had been appropriately characterized.

My discomfort stemmed from the initial goal of going against the narratives of trauma that defined refugees within the framework of bureaucratic performance. I knew that Anisa and Adnan, like many young asylum seekers, were more interested in presenting themselves as skillful and talented, instead of persecuted and traumatized. I resisted talking about their past lives and journeys to England and used theater as a tool for social integration and relief. Overcoming countless odds, Anisa and Adnan won their appeal and theater has continued to play a pivotal role in their integration. Over the last 5 years, they have gone on to act in other shows, produce their own plays, and direct scores of other theater enthusiasts. 
However, while they were going through the refugee determination process, I realized that the desire to disengage from trauma did not align with expectations of the broader bureaucratic structures. Anisa and Adnan had to provide convincing narratives of vulnerability and replacing those narratives with stories of resilience put them in danger of having their claim rejected. My role as a participatory practitioner required me to respond to and influence a legal understanding of migrant persecution. I had to be strategic in the way I framed Anisa and Adnan's resilience in my letter to the immigration judge.

\section{CONCLUSION}

This paper has provided a reflective account of the need for critical health practitioners to consider how the legal frameworks of RSD, and its associated focus on demonstrating trauma, influences the work of practitioners and researchers in profound ways. In particular, my account provides two key insights for participatory forms of research and performance practice with asylum seekers. First, asylum narratives of confidence, well-being, and sound mental health can work against asylum seekers in their legal claims. While I remain critical of the ubiquity of trauma in refugee narratives, I now recognize that participatory projects must reassess their ethical stance toward resisting narratives of migrant trauma. I had good reasons for initially not engaging with Anisa and Adnan's painful experiences. They had made it clear to me that they did not want to victimize themselves. However, when I was

\section{REFERENCES}

Balfour, M., and Woodrow, N. (2013). "On stitches," in Refugee Performance: Practical Encounters, ed M. Balfour (Bristol: Intellect Ltd), 15-34.

Coleman, D. (2012). Countering Displacements: The Creativity and Resilience of Indigenous and Refugee-ed Peoples, 1st Edn. Edmonton: The University of Alberta Press.

Conquergood, D. (1988). Health theatre in a hmong refugee camp: performance, communication, and culture. TDR 32, 174-208. doi: 10.2307/1145914

Cox, E. (2014). Theatre \& Migration. Available online at: https://search.ebscohost. com/login. asp $x$ ?direct $=$ true $\&$ scope $=s i t e \& d b=$ nlebk $\& d b=$ nlabk $\& A N=1525051$ (accessed December 23, 2019).

Dutta, M. J. (2010). The critical cultural turn in health communication: reflexivity, solidarity, and praxis. Health Commun. 25, 534-539. doi: $10.1080 / 10410236.2010 .497995$

Gibson, S. (2013). Testimony in a culture of disbelief: asylum hearings and the impossibility of bearing witness. J. Cult. Res. 17, 1-20. doi: 10.1080/14797585.2011.613221

Jeffers, A. (2008). Dirty truth: personal narrative, victimhood and participatory theatre work with people seeking asylum. Res. Drama Educ. 13, 217-221. doi: $10.1080 / 13569780802054919$

Jubany, O. (2017). "Screening asylum in a culture of disbelief," in Truths, Denials and Skeptical Borders (Cham: Palgrave MacMillan). doi: 10.1007/978-3-319-40748-7

Lupton, D. (1994). Toward the development of critical health communication praxis. Health Commun. 6, 55-67. doi: 10.1207/s15327027hc0601_4

Pestre, É. (2012). Instrumentalizing the refugee's body through evidence. Rech. Psychanalyse. 14:147. doi: 10.3917/rep.014.0147a

Salverson, J. (2001). Change on whose terms? testimony and an erotics of inguiry. Theater 31, 119-125. Available online at: https://www.muse.jhu.edu/article/ 34187 (accessed December 23, 2019). asked to write a reference letter for my participants, I had to reassess this ethical stance. Instead, and the second key insight of this account is that resilience can strategically be framed in terms of trauma to attend to the legal expectations of persecution. I used my position as an institutionally affiliated practitioner to influence the legal interpretation of my participants' narratives. If I had clung to narratives of resilience, as I was compelled to do in the theater project, I would have failed to engage with the ways in which the theater project was implicated in the legal structures of RSD. Ultimately, health communication researchers would benefit from an approach that highlights trauma and resilience as interconnected phenomena with differential impacts requiring constant attention to their political efficacy. And, as health communication funding structures may mimic the legal expectations of bureaucratic performance, practitioners and researchers must be reflexive about their approaches.

\section{AUTHOR CONTRIBUTIONS}

The author confirms being the sole contributor of this work and has approved it for publication.

\section{ACKNOWLEDGMENTS}

The author would like to thank her project participants for their trust. She is also grateful to the editor and the reviewers for their feedback, and to Sarah Dempsey for her insights throughout the drafts.

Simich, L., and Andermann, L. F. (2014). Refuge and Resilience: Promoting Resilience and Mental Health Among Resettled Refugees and Forced Migrants. Dordrecht; New York, NY: Springer. doi: 10.1007/978-94-007-7923-5

Thompson, J. (2009). Performance Affects: Applied Theatre and the End of Effect. Basingstoke: Palgrave Macmillan.

Thompson, J., and Schechner, R. (2004). Why "Social Theatre"? Drama Rev. 48, 11-16. doi: 10.1162/1054204041667767

Ticktin, M. I. (2011). Casualties of Care: Immigration and the Politics of Humanitarianism in France. Berkeley: University of California Press. doi: 10.1525/california/9780520269040.001.0001

Wake, C. (2013). To witness mimesis: the politics, ethics, and aesthetics of testimonial theatre in through the wire. Modern Drama 56, 102-125. doi: 10.3138/md.2012-0465

Willen, S. S. (2012). Migration, “illegality," and health: mapping embodied vulnerability and debating health-related deservingness. Soc. Sci. Med. 74, 805-811. doi: 10.1016/j.socscimed.2011. 10.041

Zoller, H. M., and Kline, K. N. (2008). Theoretical contributions of interpretive and critical research in health communication. Ann. Int. Commun. Assoc. 32, 89-135. doi: 10.1080/23808985.2008.11679076

Conflict of Interest: The author declares that the research was conducted in the absence of any commercial or financial relationships that could be construed as a potential conflict of interest.

Copyright (C) 2020 Misra. This is an open-access article distributed under the terms of the Creative Commons Attribution License (CC BY). The use, distribution or reproduction in other forums is permitted, provided the original author $(s)$ and the copyright owner(s) are credited and that the original publication in this journal is cited, in accordance with accepted academic practice. No use, distribution or reproduction is permitted which does not comply with these terms. 